Provided for non-commercial research and education use. Not for reproduction, distribution or commercial use.

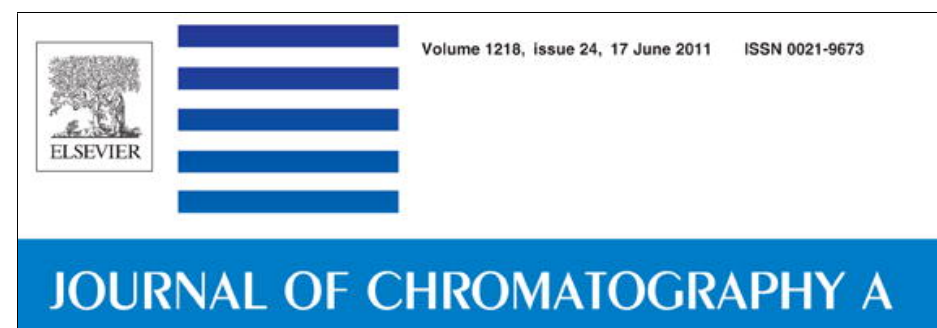

INCLUDING ELECTROPHORESIS, MASS SPECTROMETRY AND

OTHER SEPARAIION AND DEIECIION METHODS

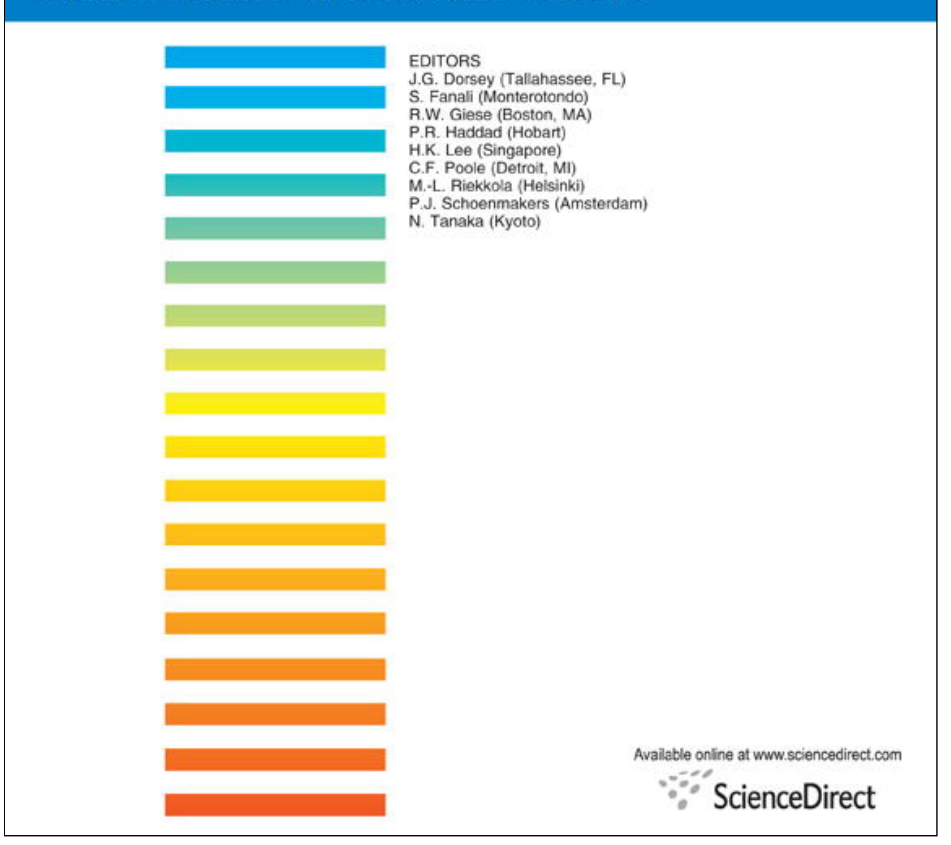

This article appeared in a journal published by Elsevier. The attached copy is furnished to the author for internal non-commercial research and education use, including for instruction at the authors institution and sharing with colleagues.

Other uses, including reproduction and distribution, or selling or licensing copies, or posting to personal, institutional or third party websites are prohibited.

In most cases authors are permitted to post their version of the article (e.g. in Word or Tex form) to their personal website or institutional repository. Authors requiring further information regarding Elsevier's archiving and manuscript policies are encouraged to visit:

http://www.elsevier.com/copyright 


\title{
Profiling allergic asthma volatile metabolic patterns using a headspace-solid phase microextraction/gas chromatography based methodology
}

\author{
M. Caldeira ${ }^{\mathrm{a}, \mathrm{b}}$, A.S. Barros ${ }^{\mathrm{a}}$, M.J. Bilelo ${ }^{\mathrm{c}}$, A. Parada ${ }^{\mathrm{c}}$, J.S. Câmara ${ }^{\mathrm{b}}$, S.M. Rocha ${ }^{\mathrm{a}, *}$ \\ a QOPNA, Departamento de Química, Universidade de Aveiro, 3810-193 Aveiro, Portugal \\ b CQM/UMa - Centro de Química da Madeira, Centro de Ciências Exactas e de Engenharia da Universidade da Madeira, Campus Universitário da Penteada, 9000-390 Funchal, Portugal \\ ${ }^{\mathrm{c}}$ Hospital Infante D. Pedro E.P.E, Avenida Artur Ravara, 3814-501 Aveiro, Portugal
}

\section{A R T I C L E I N F O}

\section{Article history:}

Received 25 January 2011

Received in revised form 8 April 2011

Accepted 11 April 2011

Available online 16 April 2011

\section{Keywords:}

Allergic asthma

Exhaled breath

Volatile metabolites

Headspace solid-phase microextraction

Gas chromatography-mass spectrometry

\begin{abstract}
A B S T R A C T
Allergic asthma represents an important public health issue with significant growth over the years, especially in the paediatric population. Exhaled breath is a non-invasive, easily performed and rapid method for obtaining samples from the lower respiratory tract. In the present manuscript, the metabolic volatile profiles of allergic asthma and control children were evaluated by headspace solid-phase microextraction combined with gas chromatography-quadrupole mass spectrometry (HS-SPME/GC-qMS). The lack of studies in breath of allergic asthmatic children by HS-SPME led to the development of an experimental design to optimize SPME parameters. To fulfil this objective, three important HS-SPME experimental parameters that influence the extraction efficiency, namely fibre coating, temperature and time extractions were considered. The selected conditions that promoted higher extraction efficiency corresponding to the higher GC peak areas and number of compounds were: DVB/CAR/PDMS coating fibre, $22^{\circ} \mathrm{C}$ and $60 \mathrm{~min}$ as the extraction temperature and time, respectively. The suitability of two containers, $1 \mathrm{~L}$ Tedlar $^{\circledR}$ bags and BIOVOC ${ }^{\circledR}$, for breath collection and intra-individual variability were also investigated. The developed methodology was then applied to the analysis of children exhaled breath with allergic asthma (35), from which 13 had also allergic rhinitis, and healthy control children (15), allowing to identify 44 volatiles distributed over the chemical families of alkanes (linear and ramified) ketones, aromatic hydrocarbons, aldehydes, acids, among others. Multivariate studies were performed by Partial Least Squares-Discriminant Analysis (PLS-DA) using a set of 28 selected metabolites and discrimination between allergic asthma and control children was attained with a classification rate of $88 \%$. The allergic asthma paediatric population was characterized mainly by the compounds linked to oxidative stress, such as alkanes and aldehydes. Furthermore, more detailed information was achieved combining the volatile metabolic data, suggested by PLS-DA model, and clinical data.
\end{abstract}

(C) 2011 Elsevier B.V. All rights reserved.

\section{Introduction}

Asthma is defined as a chronic inflammatory disorder with intermittent symptoms of cough, dyspnoea, wheezing and chest pain. Allergic asthma represents an important public health issue with significant growth over the years and affects individuals of all ages from infants to the elderly prevailing as the major cause of illness and consequent hospitalization in children of developed countries altering both patients and families' normal activities and therefore impairing life quality. Allergic asthma is also associated with high direct and indirect health costs, especially related with diagnosis and treatment. It is estimated that globally the total cost spent with

\footnotetext{
* Corresponding author. Tel.: +351 234401524; fax: +351234370084.

E-mail address: smrocha@ua.pt (S.M. Rocha).
}

allergic asthma patients is 4 times higher to those of general population and only in the European Community represents several billion Euros [1].

Currently, diagnosis is based upon symptoms and in the measurement of non-specific and broad biomarkers (for example, Immunoglobulin E-IgE). As molecular diagnosis is the next generation of personalized medicine [2] an objective of the purposed work is to contribute for the interdisciplinary link between physicians and biochemists, providing tools for a more efficient and precise diagnosis. Exhaled breath is a rich source, as found out by Pauling in the 1970s, with the identification of 250 metabolites beside nitrogen, oxygen and water vapour [3]. The development of new and more efficient extraction methods, as well as, more sensitive and efficient separation techniques led to a significant progress in this research area. The analysis and characterization of exhaled breath became a new approach with potential to provide valuable information about respiratory and systemic diseases that can lead to 
a deeper knowledge of human health status, in the identification of disease-related marker compounds and consequently a potential information source regarding the knowledge of these diseases metabolic pathways. Exhaled breath is a non-invasive, easily performed and rapid sampling, either in the gaseous or condensed state. For example in the gaseous state, the purpose of the present manuscript, there have been studies in asthma [4], cystic fibrosis [5] and lung cancer [6,7].

Although several breath biomarkers have been reported, their clinical usefulness and meaningfulness has been questioned because of the lack of established sampling and measurement procedures in the analysis of volatile compounds at trace levels. Some volatile compounds are of endogenous origin and generated by the human body during normal metabolic processes, some are inhaled with subsequent storage and later exhalation. Distinguishing endogenous compounds from inspiratory contaminants is not always straightforward. The pattern of volatile compounds in inhaled air is absolutely necessary information, in particular, when the biochemical background of the compounds found is unclear [8]. Volatiles in ambient air originate from various biogenic and anthropogenic sources and are an important class of airborne contaminants [9]. Therefore, the knowledge of ambient air volatile composition is essential to understand the potential influence of exogenous compounds. Thus, parallel sampling of exhaled breath and ambient air is highly recommended.

Several studies have been carried out in exhaled breath using different techniques, with special highlight to the use of desorption tubes filled with a suitable adsorbent $[10,11]$ and solid-phase microextraction (SPME) [12]. SPME has demonstrated an enormous potential in exhaled breath analysis and has been applied in the analysis of chemical substances present in nanomolar range. The widespread application of SPME is attributed for its solventfree feature, it is simple to use, it combines analyte extraction and pre-concentration in a single process allowing direct desorption in the chromatographic system. The extraction of analytes in SPME depends on the absorbent coating of the fibre, as well as on experimental parameters, like time and temperature of extraction, and matrix composition [13].

There have been no reports using HS-SPME methodology for the analysis of allergic asthma exhaled breath, specifically in the paediatric population. Studies have been developed using HS-SPME in order to establish the volatile composition of human exhaled breath [8] or for a specific type of disease, for example diabetes [14], lung cancer [15] and cystic fibrosis [16] or for chemical substances exposure monitoring [17]. Studies concerning non invasive monitoring of allergic airway inflammation have been made using exhaled nitric oxide [18] or breath condensate [19]. The lack of a prominent HS-SPME study in allergic asthma exhaled breath led us to develop an experimental design by combining HS-SPME with gas chromatography-quadrupole mass spectrometry (GC-qMS) to assess information from allergic asthma metabolomic patterns. To fulfil these objectives three important HS-SPME experimental parameters that influence the extraction efficiency, namely extraction temperature and time, and coating fibre were considered. A full factorial design was applied to determine the best extraction conditions using different chemical standards (hydrocarbons, aldehydes, ketones, aromatic and aliphatic alcohols) reported in literature to be present in exhaled breath $[8,20,21]$. Some exhaled breath sampling parameters were also optimized. Two different breath sampling containers were tested, Tedlar ${ }^{\circledR}$ gas sampling bags and BIOVOCS ${ }^{\circledR}$ and the washing procedure of the chosen container was optimized. Another important parameter, the intra-individual variability, was checked over a period of three weeks with sampling throughout a single day. After this optimization, the proposed methodology was applied to the analysis of children exhaled breath with allergic asthma and healthy children, used as control.
Table 1

Characteristics of the studied population: allergic asthma and healthy controls.

\begin{tabular}{|c|c|c|}
\hline & Allergic asthma $(n=35)$ & Control $(n=15)$ \\
\hline $\begin{array}{l}\text { Age in years } \\
\quad(\text { mean } \pm \mathrm{SD}) /(\text { range })\end{array}$ & $8.5 \pm 2.5 / 4-13$ & $8.0 \pm 3.1 / 4-13$ \\
\hline Gender (male/female) & $13 / 22$ & $7 / 8$ \\
\hline \multicolumn{3}{|l|}{ Pathology } \\
\hline Allergic asthma (AA) & $22(63 \%)$ & - \\
\hline $\begin{array}{l}\text { Allergic asthma + allergic } \\
\text { rhinitis }(A A+A R)\end{array}$ & $13(37 \%)$ & - \\
\hline \multicolumn{3}{|l|}{ Allergens $^{a}$} \\
\hline Dust mite & $19(54 \%)$ & - \\
\hline Dust mite + cat fur & $3(9 \%)$ & - \\
\hline Dust mite + gramineae & $3(9 \%)$ & - \\
\hline Dust mite + cat fur + gramineae & $1(3 \%)$ & - \\
\hline $\begin{array}{l}\text { Information not available } \\
\text { Therapy }\end{array}$ & $9(25 \%)$ & - \\
\hline $\begin{array}{l}\text { Corticosteroid + leukotriene } \\
\text { receptor antagonist }\end{array}$ & $12(34 \%)$ & - \\
\hline $\begin{array}{l}\text { Corticosteroid and } \\
\text { anti-histamines }\end{array}$ & $4(12 \%)$ & - \\
\hline $\begin{array}{l}\text { Corticosteroid and } \\
\text { bronchodilator }\end{array}$ & $13(37 \%)$ & - \\
\hline No therapy & $6(17 \%)$ & - \\
\hline
\end{tabular}

${ }^{a}$ Results obtained by prick-tests.

\section{Experimental}

\subsection{Standards and materials}

The reagents used were of analytical grade and from different chemical families: linear hydrocarbons (hexane $(99.5 \%$, Fluka, Madrid, Spain), undecane (99.8\%, Fluka, Madrid, Spain)), aldehydes (hexanal (98\%, Sigma-Aldrich, Madrid, Spain), (E)-2nonenal (95\%, Acros Organics, Geel Belgium)), ketones (acetone (99.5\%, Fluka, Madrid, Spain), 3-heptanone (97\%, Sigma-Aldrich, Madrid, Spain)), and aromatic and aliphatic alcohols (phenol (99\%, Merck, New Jersey, USA), 1-hexanol (98\%, Sigma-Aldrich, Madrid, Spain)). Absolute ethanol was supplied by Panreac (99.5\%, analytical grade, Barcelone, Spain). Ultra pure water was obtained from a Milli-Q system from Millipore (Milford, MA, USA). Four different fibres from Supelco (Bellefonte, PA, USA) were used: divinylbenzene/carboxen/polydimetylsiloxane (DVB/CAR/PDMS, 50/30 $\mu \mathrm{m}$ ), polydimetylsiloxane/divinylbenzene (PDMS/DVB, $65 \mu \mathrm{m}$ ), polydimetylsiloxane (PDMS, $100 \mu \mathrm{m}$ ) and polyacrilate (PA, $85 \mu \mathrm{m}$ ). SPME fibres and SPME manual holder was obtained from Supelco (Bellenfonte, PA, USA). All the fibres were of the same length $(1 \mathrm{~cm})$ and conditioned prior to use, as recommended by the manufacturer. $1 \mathrm{~L}$ Tedlar ${ }^{\circledR}$ bags (SKC Inc., Eighty Four, PA, USA) and BIOVOCS $^{\circledR}$ (Markes International, Llanstrisant, UK) were used for sampling.

\subsection{Breath samples}

A group of 35 children with allergic asthma, from which 13 had allergic rhinitis, and 15 healthy control children volunteered for this study. All parents signed an informed consent for participation in the study. The children with allergic asthma were recruited from the outpatient clinic of the department of paediatric immunoalergology of Hospital D. Pedro (Aveiro, Portugal) while controls were recruited at the local facilities that presented no asthma episodes or symptoms. Asthma diagnosis was made based on clinical symptoms and exams (skin prick tests and IgE values). Appropriate therapy was prescribed by the patient's own physician. All allergic asthma population represented a controlled asthma status. The characteristics of the patients and controls are presented in Table 1. No restrictions were applied regarding drugs or diet and all allergic asthma subjects were sampled in the same room at the 
local hospital. The study was approved by the local hospital ethics committee.

\subsection{Experimental design}

Different chemical standards were used to perform the full factorial design: hexane, acetone, hexanal, 3-heptanone, undecane, 1-hexanol, (E)-2-nonenal and phenol. A stock solution of each standard $(1 \mathrm{~g} / \mathrm{L})$ was prepared in absolute ethanol and made up to volume, and from this a solution of $100 \mathrm{mg} / \mathrm{L}$ was set up. A working solution was prepared to yield different concentrations from $0.4 \mathrm{mg} / \mathrm{L}$ (undecane) to $1.6 \mathrm{mg} / \mathrm{L}$ (hexanal). To reproduce a two-phase system (headspace and coating fibre), as in breath analysis, $50 \mu \mathrm{L}$ was added to a $120 \mathrm{~mL}$ SPME flask and sealed with an aluminium crimp cap with a vial was capped with a PTFE septum (Chromacol, Hertfordshire, UK) and concentrations ranged from 166.7 to $670.0 \mathrm{ng} / \mathrm{L}$. Three important SPME experimental parameters were considered on this study: coating fibre, extraction time and temperature. Four different fibres, DVB/CAR/PDMS, PDMS/DVB, PDMS and PA, were tested and compared. Before daily analysis each fibre was conditioned for $15 \mathrm{~min}$ at $250^{\circ} \mathrm{C}$. Two different temperatures $\left(5\right.$ and $22^{\circ} \mathrm{C}$ ) and five different extraction times $(5,15,30,45$ and $60 \mathrm{~min})$ were evaluated.

\subsection{Breath analysis}

\subsubsection{Breath sampling containers}

The suitability of two breath sampling containers was tested and from the wide range available commercially Tedlar ${ }^{\circledR}$ gas sampling bags and BIOVOC ${ }^{\circledR}$ were chosen. All tests were made using the exhaled breath of a child with allergic asthma and using the method developed in the experimental design.

Tedlar $^{\circledR}$ gas sampling bags were chosen and due to impurities, derived from the manufacturing process, the washing procedure was verified as the manufacturer suggests. Prior to this step, the purity of the compressed air/nitrogen available in the laboratory was verified and the main conclusion is that the used gases are adequate for this procedure as there is no further contamination by these washing agents (data not shown). The manufacturer recommends that before using Tedlar $^{\circledR}$ bags three nitrogen/compressed air flushes should suffice, however the comparison was made between no flush, 3 and 10 nitrogen flushes.

\subsubsection{Breath sampling}

Exhaled breath was collected in $1 \mathrm{~L}$ Tedlar ${ }^{\circledR}$ bags with parallel ambient air extraction. Breath samples were obtained while children waited for consultation. Children were asked to cleanse their mouth with water before sampling. Subsequently, children were instructed to inhale and exhaled normally and then exhale deeply into the Tedlar $^{\circledR}$ bag previously holding their breath for $5 \mathrm{~s}$. The collection method was successfully done by all volunteers. Each subject provided one sample using a disposable mouthpiece. Before collecting exhaled breath, all bags were thoroughly cleaned to remove residual contaminants by flushing with high purity nitrogen gas allowing the re-use of the Tedlar ${ }^{\circledR}$ bags. The bags were transported to the laboratory and the analysis was performed to a maximum of $6 \mathrm{~h}$ as recommended by Mochalski et al. [22]. On average, the analysis was performed $2-3 \mathrm{~h}$ after sampling. The bags were storage at $22^{\circ} \mathrm{C}$. Parallel room air sampling was also performed using a large volume syringe to fill a Tedlar bag with room air.

\subsubsection{Intra-individual variability evaluation}

There have been reports on the intra-individual variation of exhaled breath over a period of time [23]. This is an important parameter to be assessed for the developed methodology to verify if the individual profile is repeatable or consistent over time. Hence, the exhaled breath of a child with allergic asthma was collected over a period of three consecutive weeks, six replicates were performed and analysed in the same day. All sampling was performed in the same room.

\subsubsection{HS-SPME general procedure}

Breath analysis was performed with the optimized conditions using the DVB/CAR/PDMS fibre in a $22^{\circ} \mathrm{C}$ thermostated room for $60 \mathrm{~min}$. Following the extraction procedure, the SPME fibre was retracted from the Tedlar ${ }^{\circledR}$ bag and inserted in the GC system injection port for $5 \mathrm{~min}$ where the compounds were thermally desorbed and transferred to the GC column.

\subsection{GC-qMS analysis}

The SPME coating fibre containing the volatile compounds from the standard working solution and exhaled breath was manually introduced into the GC injection port at $250^{\circ} \mathrm{C}$ and kept for $5 \mathrm{~min}$ for desorption. The injection port was lined with a $0.75 \mathrm{~mm}$ I.D. glass liner. The desorbed volatile compounds were analysed in an Agilent Technologies $6890 \mathrm{~N}$ Network gas chromatograph, equipped with a $60 \mathrm{~m} \times 0.32 \mathrm{~mm}$ I.D., $0.25 \mu \mathrm{m}$ film thickness DB-FFAP fused silica capillary column (J\&W Scientific, Folsom, CA, USA), connected to an Agilent 5973 quadrupole mass selective detector. Splitless injections were used $(5 \mathrm{~min})$. The oven temperature program was set initially to $50^{\circ} \mathrm{C}$, with a temperature increase of $5^{\circ} \mathrm{C} / \mathrm{min}$ to $220^{\circ} \mathrm{C}$ held ( $6 \mathrm{~min})$. Helium carrier gas had a flow rate of $1.7 \mathrm{~mL} / \mathrm{min}$ and the column head pressure was 12 psi. The mass spectrometer was operated in the electron impact mode (EI) at $70 \mathrm{eV}$ scanning the range $33-300 \mathrm{~m} / \mathrm{z}$ in a 4.76-s cycle, in a full scan acquisition mode. The identification of the chromatogram peaks was done comparing all mass spectra with the library data system of the GC-qMS equipment (NIST 05 MS Library). The spectra were also compared with spectra found in the literature. The identification of each volatile compound was confirmed by comparing its mass spectrum and retention time with those of the pure standard compounds, when available. The GC peak area data were used as an indirect approach to estimate the relative content of each volatile compound. All measurements concerning the chemical standards were made with three replicates and the reproducibility was expressed as Relative Standard Deviation (RSD \%). Each breath represents a single sample, and was analysed once. To verify the absence of any carry over, blanks, corresponding to the analysis of the coating fibre not submitted to any extraction procedure, were run between sets of three analyses.

\subsection{Statistical analysis}

Single factor ANOVA was performed in the evaluation of the intra-individual variability over a period of three weeks. A critical value of 0.05 was used as a criterion of significance and all calculations were performed using the Excel ${ }^{\circledR}$ software (Microsoft). Partial Least Squares (PLS) is a very important procedure for both regression and classification purposes. Concerning the classification application of PLS, known as Partial Least Squares-Discriminant Analysis (PLS-DA) [24], the most common approach is to use a $\mathbf{Y}$ matrix containing dummy variables which defines sample memberships to pre-defined groups and allow to extract relevant information/variability that could describe the reasons for the observed patterns (clusters). This methodology allows one to understand which variables (metabolites) contribute the most for the observed separation. The PLS-DA was applied to volatile metabolites compositional data (28) identified by HSSPME/GC-qMS present in all the samples (50) and for classification purposes were used two groups (control and asthma). The clas- 


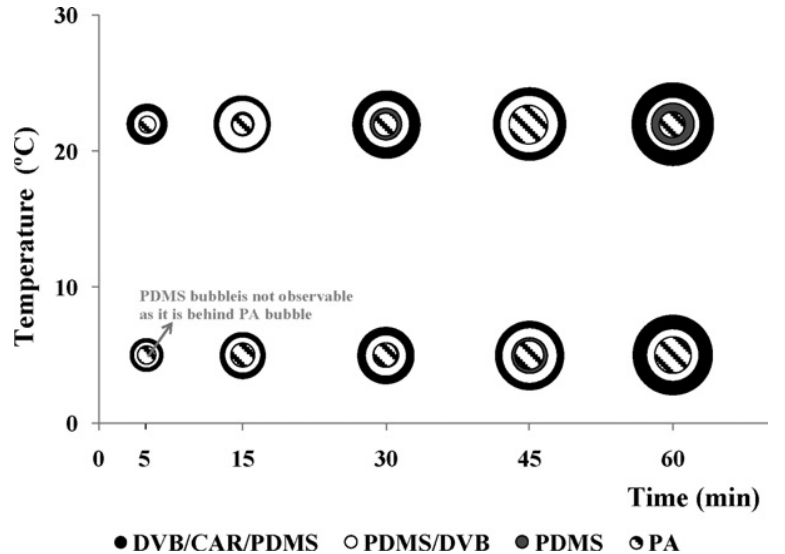

Fig. 1. Full factorial design of solid-phase microextraction conditions for GC-qMS analysis of exhaled breath.

sification model complexity (number of latent variables) and classification rate were estimated by internal cross-validation ( 7 blocks splits).

\section{Results and discussion}

\subsection{Experimental design: HS-SPME optimization}

The first stage of this study addressed the HS-SPME parameters optimization that influences the extraction process. Different chemical standards reported in literature $[8,15]$ to be present in exhaled breath were used: hexane, acetone, hexanal, 3-heptanone, undecane, 1-hexanol, (E)-2-nonenal and phenol. Experimental design allows estimating the effect of several variables simultaneously and the complete factorial design enabled the evaluation of three significant factors that greatly influences the vapour pressure and equilibrium of the target compounds in the headspace, therefore affecting the extraction efficiency: fibre coating (DVB/CAR/PDMS, PDMS/DVB, PDMS and PA), temperature (5 and $\left.22^{\circ} \mathrm{C}\right)$ and extraction time $(5,15,30,45$ and $60 \mathrm{~min})$ with a total of 120 runs being performed. The obtained results can be seen in Fig. 1, in which each bubble represents the total chromatographic area of the eight standards under study inherent to three different variables (extraction temperature, extraction time and SPME fibre coating). Through the bubble illustration, shown in Fig. 1, it is easy to evaluate the overall extraction efficiency, since a larger bubble represents a higher total chromatographic area.

The comparison was made in terms of total extraction efficiency and reproducibility. The highest extraction efficiency was obtained using the DVB/CAR/PDMS fibre in all studied extraction times and temperatures while PA $\left(22^{\circ} \mathrm{C}\right)$ and PDMS $\left(5^{\circ} \mathrm{C}\right)$ showed the lowest sorptive capacity. The nature of the analytes influences the SPME fibre selection. Previous reports $[7,25]$ on exhaled breath analysis used PDMS because these studies were focused in alkanes and aromatic hydrocarbons. These compounds are non-polar, so it is preferable a PDMS phase. The methodology optimized in the present manuscript is to be used in a wide range of analytes, which explains that DVB/CAR/PDMS fibre obtained the best results, as its stationary phase has a synergistic effect between adsorption and absorption. The mutually synergetic effect of adsorption and absorption of the stationary phase promotes a high retention capacity and, consequently, a higher sensitivity than fibres based on absorption only. Therefore, as DVB/CAR/PDMS presents a wide range capacity of sorbing compounds and it is recommended by the producers in the analysis of compounds with different physicochemical properties within a molecular weight ranging from 40 to 275 .

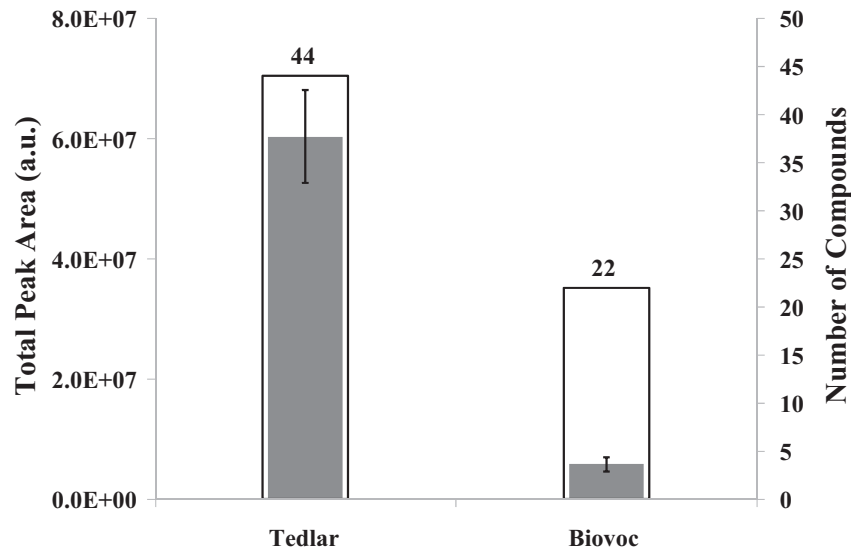

Fig. 2. Total peak area and number of compounds comparison between two breath collection containers (Tedlar ${ }^{\circledR}$ gas sampling bags and BIOVOC $^{\circledR}$ ). a.u. - arbitrary units.

The extraction time was studied by increasing the fibre exposure time from 5 to $60 \mathrm{~min}$. Higher extraction time promoted higher extraction efficiency for all the fibres under study. For the selected standards, higher extraction efficiency was achieved with an extraction time of $60 \mathrm{~min}$. Although this is a long extraction time, maximum sensitivity is desirable, at this particular stage, so that the knowledge of exhaled breath is maximized.

The SPME process is also influenced by temperature. Higher extraction temperature usually increases the analytes release, therefore increasing their concentration in the headspace, due to the enhanced mass transfer (kinetics). Two temperatures were studied: $5^{\circ} \mathrm{C}$ and $22^{\circ} \mathrm{C}$ (room air temperature). Higher temperatures were avoided because heating these containers could possibly release contaminants or produce artifacts to the headspace, therefore influencing the results. For all fibres and extraction times under study, $22^{\circ} \mathrm{C}$ allowed higher extraction efficiency.

The extraction at $22^{\circ} \mathrm{C}$ for $60 \mathrm{~min}$ with the SPME coating fibre DVB/CAR/PDMS was selected for further breath extractions. For the selected conditions, RSD was considered acceptable (10\%).

\subsection{Breath analysis}

Beside the HS-SPME optimization for breath analysis there are several factors that have to be considered and optimized. Among the factors, we optimized the type of breath sampling containers used, the cleaning procedure adopted to such containers as well as an important parameter such as intra-individual variability. After these optimization steps, the developed methodology was applied to a set of 50 children ( 35 with allergic asthma, among these 13 had also allergic rhinitis and 15 healthy controls).

\subsubsection{Breath sampling containers}

There are a wide range of methods for sampling exhaled breath, which can include canisters, cold trapping, adsorbing agents, BIOVOC $^{\circledR}$, Teflon and Tedlar ${ }^{\circledR}$ gas sampling bags. These containers should be easy to operate, easy to handle and be able to store a sample for a prolonged period of time (in breath sampling the storage time is a major drawback). Cost, re-usability, durability, size and versatility are other important issues to take in consideration when choosing the adequate container. As a result, Tedlar ${ }^{\circledR}$ gas sampling bags and BIOVOC ${ }^{\circledR}$ were chosen for further studies.

The suitability of two sampling containers Tedlar ${ }^{\circledR}$ gas sampling bags and BIOVOC $^{\circledR}$ was investigated using the exhaled breath of a child with allergic asthma with the previously developed HSSPME methodology. Taking into consideration the obtained results (Fig. 2), Tedlar $^{\circledR}$ bags are the best choice for sampling exhaled 
Table 2

Volatiles identified in Tedlar bags and cleansing procedure effects with rising number of nitrogen flushes.

\begin{tabular}{|c|c|c|c|c|c|}
\hline \multirow[t]{2}{*}{ Retention time (min) } & \multirow[t]{2}{*}{ Compounds } & \multirow[t]{2}{*}{ CAS number } & \multicolumn{3}{|c|}{ Volatiles identified in Tedlar bags } \\
\hline & & & No nitrogen flushes & 3 nitrogen flushes & 10 nitrogen flushes \\
\hline \multicolumn{6}{|l|}{ Linear alkanes } \\
\hline 6.34 & Hexane $^{a}$ & $110-54-3$ & $\mathrm{x}$ & $\mathrm{x}$ & $\mathrm{x}$ \\
\hline 7.20 & 2,4-Dimethyl-heptane & $2213-23-2$ & $\mathrm{x}$ & n.d. & n.d. \\
\hline 7.65 & 4-Methyl-octane & $2216-34-4$ & $\mathrm{x}$ & n.d. & n.d. \\
\hline 11.40 & Undecane $^{\mathrm{a}}$ & $1120-21-4$ & $\mathrm{x}$ & n.d. & n.d. \\
\hline \multicolumn{6}{|l|}{ Carbonyl compounds } \\
\hline 7.39 & Acetone $^{\mathrm{a}}$ & $67-64-1$ & $\mathrm{x}$ & $\mathrm{x}$ & n.d. \\
\hline 26.48 & Benzaldehyde $^{\mathrm{a}}$ & $100-52-7$ & $\mathrm{x}$ & $\mathrm{x}$ & $\mathrm{x}$ \\
\hline 21.10 & Acetic acid $^{\mathrm{a}}$ & $64-19-7$ & $\mathrm{x}$ & $\mathrm{x}$ & $\mathrm{x}$ \\
\hline \multicolumn{6}{|l|}{ Aromatic compounds } \\
\hline 33.77 & Phenol $^{\mathrm{a}}$ & $108-95-2$ & $\mathrm{x}$ & $\mathrm{x}$ & $\mathrm{x}$ \\
\hline 13.56 & dMethEthBenz ${ }^{\mathrm{b}}$ & $1075-38-3$ & $\mathrm{x}$ & $\mathrm{x}$ & $\mathrm{x}$ \\
\hline 14.32 & $m / z 105,122,91$ & - & $\mathrm{x}$ & $\mathrm{x}$ & $\mathrm{x}$ \\
\hline \multicolumn{6}{|l|}{ Miscellaneous } \\
\hline 8.57 & Dichloromethane $\mathrm{a}^{\mathrm{a}}$ & $75-09-2$ & $\mathrm{x}$ & $\mathrm{x}$ & $\mathrm{x}$ \\
\hline 10.20 & $\alpha$-pinene ${ }^{\mathrm{a}}$ & $80-56-8$ & $\mathrm{x}$ & $\mathrm{x}$ & $\mathrm{x}$ \\
\hline 10.10 & Chloroform ${ }^{\mathrm{a}}$ & $67-66-3$ & $\mathrm{x}$ & $\mathrm{x}$ & n.d. \\
\hline 25.23 & (N,N-dimethyl)-acetamide & $127-19-5$ & $\mathrm{x}$ & $\mathrm{x}$ & $\mathrm{x}$ \\
\hline 35.18 & Diethyl phthalate & $84-66-2$ & $\mathrm{x}$ & $\mathrm{x}$ & $\mathrm{x}$ \\
\hline 36.71 & Phthalate isobutyrate & $103-28-6$ & $\mathrm{x}$ & $\mathrm{x}$ & $\mathrm{x}$ \\
\hline
\end{tabular}

n.d. - not detected.

a Compounds confirmed by chemical standards.

b dMethEthBenz: 1-(1,1-dimethylethyl)-3-methyl-benzene.

breath. There was a great difference between both containers with the identification of forty-four compounds for samples stored in Tedlar $^{\circledR}$ bags, while for samples stored in BIOVOC ${ }^{\circledR}$ twenty-two were identified. In terms of total peak area, the difference between BIOVOC $^{\circledR}$ and Tedlar ${ }^{\circledR}$ bag was considerable as BIOVOC ${ }^{\circledR}$ total peak area only represented $10 \%$ of the obtained by using the Tedlar ${ }^{\circledR}$ bag. For follow-up procedures, the Tedlar ${ }^{\circledR}$ bag was chosen.

Tedlar $^{\circledR}$ bags are frequently used to collect exhaled breath [26] as it fulfils the requisites for sampling and storing this type of samples. Nevertheless, Tedlar ${ }^{\circledR}$ bags have two main disadvantages: (1) impurities derived from the manufacturing process and (2) sample leakage due to adsorption or diffusion through the walls. The manufacturer recommends flushing the bag three times with compressed air or nitrogen before use so that the contaminants are eliminated. The effectiveness of this routine on Tedlar ${ }^{\circledR}$ bags was evaluated from no flush, flushing three and ten times using the previously HS-SPME/GC-qMS developed methodology. Blank runs were made, filling the Tedlar ${ }^{\circledR}$ gas sampling bags with compressed air and several pollutants, a total of sixteen compounds, were identified (Table 2). Increasing the number of nitrogen flushes produces a positive result as the number of compounds diminishes. Nevertheless, a more detailed overview of these results is demonstrated taking into consideration two contaminants reported in literature [26], ( $N, N$-dimethyl)acetamide and phenol. There is a significant reduction of the total peak areas with the increase of number of flushes. For ( $N, N$-dimethyl)acetamide, the total peak area diminished $74 \%$ and $94 \%$ whereas for phenol the reductions were of $57 \%$ and $99 \%$ with three and ten flushes respectively, relatively to the initial composition (no flush) (Fig. 3). For further analysis, Tedlar ${ }^{\circledR}$ bags were vacuumed and flushed ten times with nitrogen. With

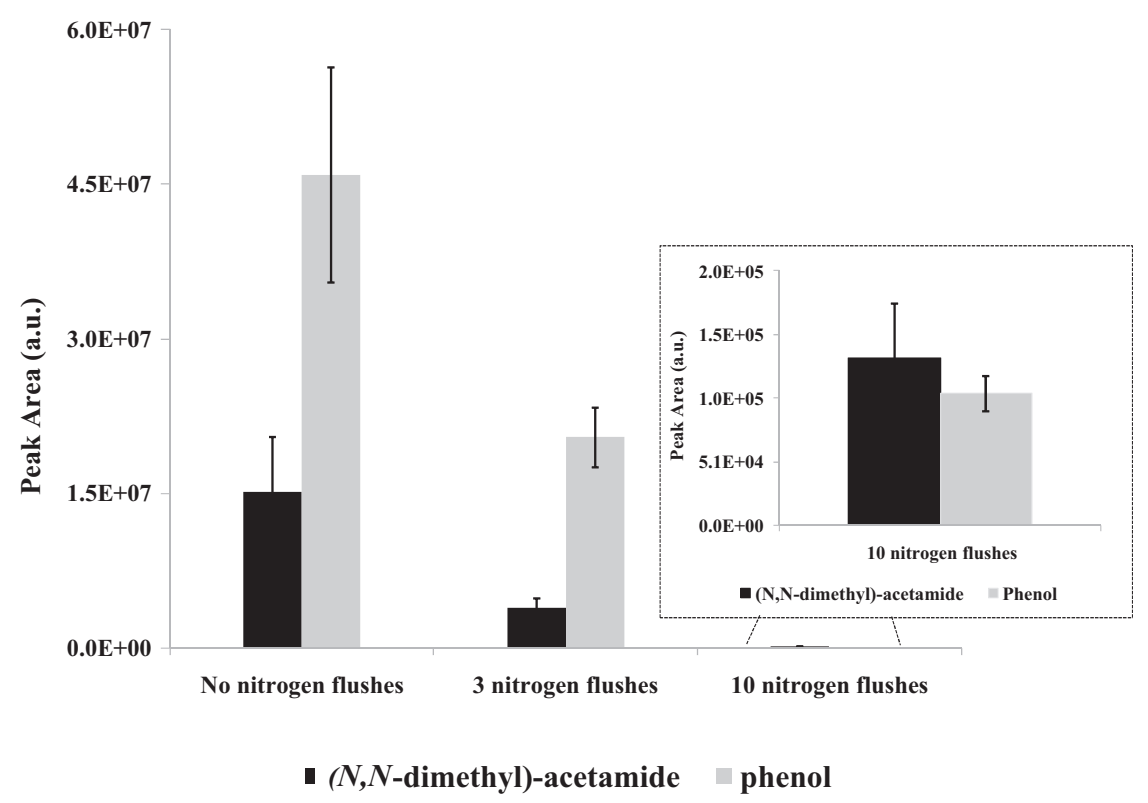

Fig. 3. Cleaning procedure effects with rising number of nitrogen flushes for two reported contaminants ((N,N-dimethyl)-acetamide and phenol) in Tedlar bags. a.u. - arbitrary units. 
Table 3

Identified compounds in exhaled breath in both children with allergic asthma and control children and obtained from ambient air parallel sampling.

\begin{tabular}{|c|c|c|c|c|c|c|}
\hline Peak number & R.T. (min) & Compounds & CAS number & $m / z$ & Breath & Ambient air \\
\hline & & Alkanes & & & & \\
\hline 1 & 6.34 & Hexane $^{a}$ & $110-54-3$ & $57^{\mathrm{b}}, 43,41$ & $\mathrm{x}$ & $\mathrm{x}$ \\
\hline 3 & 7.20 & 2,4-Dimethylheptane & $2213-23-2$ & $43,57,85$ & $\mathrm{x}$ & n.d. \\
\hline 5 & 7.65 & 4-Methyloctane & $2216-34-4$ & $43,41,85$ & $\mathrm{x}$ & $\mathrm{x}$ \\
\hline 6 & 8.94 & 2,2,4-Trimethylhexane & $16747-26-5$ & $57,56,41$ & $\mathrm{x}$ & $\mathrm{x}$ \\
\hline 7 & 9.57 & Decane $^{a}$ & $124-18-5$ & $43,57,41$ & $\mathrm{x}$ & n.d. \\
\hline 8 & 10.19 & 3,3-Dimethylheptane & $4032-86-4$ & $43,57,71$ & $\mathrm{x}$ & n.d. \\
\hline 10 & 10.29 & 2,4-Dimethyloctane & $4032-94-4$ & $57,71,85$ & $\mathrm{x}$ & n.d. \\
\hline 12 & 11.15 & 3-Ethyl-3-methylheptane & $17302-01-1$ & $71,43,85$ & $\mathrm{x}$ & n.d. \\
\hline 13 & 11.27 & 2,3,7-Trimethyldecane & $62238-13-5$ & $43,71,57$ & $\mathrm{x}$ & n.d. \\
\hline 14 & 11.40 & Undecane ${ }^{a}$ & $1120-21-4$ & $71,43,57$ & $\mathrm{x}$ & n.d. \\
\hline 16 & 11.61 & 2,3-Dimethyldecane & $17312-44-6$ & $71,43,85$ & $\mathrm{x}$ & n.d. \\
\hline 19 & 14.10 & Dodecane $^{\mathrm{a}}$ & $112-40-3$ & $57,43,71$ & $\mathrm{x}$ & $\mathrm{x}$ \\
\hline 21 & 15.15 & 3,9-dimethylundecane & $17301-31-4$ & $71,57,43$ & $\mathrm{x}$ & n.d. \\
\hline 25 & 16.56 & 3,6-Dimethyldecane & $13150-81-7$ & $71,43,57$ & $\mathrm{x}$ & n.d. \\
\hline 26 & 16.57 & Tridecane $^{\mathrm{a}}$ & $629.50-5$ & $57,43,71$ & $\mathrm{x}$ & n.d. \\
\hline 28 & 16.82 & n.i. & - & $43,71,57$ & $\mathrm{x}$ & n.d. \\
\hline 29 & 17.11 & n.i. & - & $71,57,43$ & $\mathrm{x}$ & n.d. \\
\hline 31 & 17.42 & 2,5,6-Trimethyldecane & $62108-23-0$ & $71,57,43$ & $\mathrm{x}$ & n.d. \\
\hline 33 & 19.35 & Tetradecane $\mathrm{a}^{\mathrm{a}}$ & $629-59-4$ & $57,43,71$ & $\mathrm{x}$ & $\mathrm{x}$ \\
\hline 38 & 21.64 & Pentadecane $\mathrm{a}^{\mathrm{a}}$ & $629-62-9$ & $71,43,85$ & $\mathrm{x}$ & $\mathrm{x}$ \\
\hline 39 & 21.90 & n.i. & - & $43,85,71$ & $\mathrm{x}$ & n.d. \\
\hline 41 & 22.50 & n.i. & - & $57,71,85$ & $\mathrm{x}$ & n.d. \\
\hline 42 & 22.73 & n.i. & - & $71,43,57$ & $\mathrm{x}$ & $\mathrm{x}$ \\
\hline 47 & 24.30 & Hexadecane ${ }^{a}$ & $544-76-3$ & $57,43,71$ & $\mathrm{x}$ & n.d. \\
\hline 48 & 25.08 & 2-Methyl-tridecane & $1560-96-9$ & $57,43,71$ & $\mathrm{x}$ & n.d. \\
\hline 52 & 25.86 & 2,6,10-Trimethyldodecane & $3891-98-3$ & $57,71,43$ & n.d. & $\mathrm{x}$ \\
\hline 53 & 26.24 & 2-Methylpentadecane & $1560-93-6$ & $57,43,71$ & $\mathrm{x}$ & $\mathrm{x}$ \\
\hline 59 & 28.26 & $\begin{array}{l}\text { n.i. } \\
\text { Ketones }\end{array}$ & - & $57,71,85$ & n.d. & $\mathrm{x}$ \\
\hline 4 & 7.39 & Acetone $^{\mathrm{a}}$ & $67-64-1$ & $43,58,42$ & $\mathrm{x}$ & $\mathrm{x}$ \\
\hline 30 & 17.27 & Cyclohexanone $\mathrm{e}^{\mathrm{a}}$ & $108-94-1$ & $55,98,42$ & n.d. & $\mathrm{x}$ \\
\hline 32 & 18.08 & 6-Methyl-5-hepten-2-one & $110-93-0$ & $43,41,69$ & $\mathrm{x}$ & $\mathrm{x}$ \\
\hline 54 & 26.48 & $\begin{array}{l}\text { Acetophenone }^{\mathrm{a}} \\
\text { Terpenic compounds }\end{array}$ & $98-86-2$ & $105,120,77$ & $\mathrm{x}$ & $\mathrm{x}$ \\
\hline 9 & 10.20 & $\alpha$-Pinene ${ }^{\mathrm{a}}$ & $80-56-8$ & $93,92,91$ & n.d. & $\mathrm{x}$ \\
\hline 17 & 12.15 & $\alpha$-Phellandrene ${ }^{\mathrm{a}}$ & $99-83-2$ & $93,77,79$ & n.d. & $\mathrm{x}$ \\
\hline 20 & 14.39 & Limonene $^{\mathrm{a}}$ & $138-86-3$ & $68,67,93$ & n.d. & $\mathrm{x}$ \\
\hline 51 & 25.61 & Menthol $^{\mathrm{a}}$ & $1490-04-6$ & 71,95 & n.d. & $\mathrm{x}$ \\
\hline 63 & 30.48 & $\begin{array}{l}\text { Nerylacetone }^{\mathrm{a}} \\
\text { Aromatic hydrocarbons }\end{array}$ & $3879-26-3$ & $43,69,107$ & n.d. & $\mathrm{x}$ \\
\hline 11 & 10.93 & Toluene $^{\mathrm{a}}$ & $108-88-3$ & $91,92,65$ & $\mathrm{x}$ & $\mathrm{x}$ \\
\hline 18 & 13.02 & $p$-Xylene ${ }^{\mathrm{a}}$ & $106-42-3$ & $91,106,65$ & $\mathrm{x}$ & $\mathrm{x}$ \\
\hline 24 & 16.21 & Styrene & $100-42-5$ & $104,103,78$ & $\mathrm{x}$ & n.d. \\
\hline 60 & 28.72 & Napthalene ${ }^{a}$ & $91-20-3$ & $128,120,102$ & n.d. & $\mathrm{x}$ \\
\hline 76 & 37.23 & $\begin{array}{l}\text { 2,6bmethnapth } \\
\text { Aldehydes }\end{array}$ & 24157-81-1 & $197,212,155$ & n.d. & $\mathrm{x}$ \\
\hline 15 & 11.51 & Hexanal $^{\mathrm{a}}$ & $66-25-1$ & $44,56,41$ & n.d. & $\mathrm{x}$ \\
\hline 34 & 19.55 & Nonanal $^{\mathrm{a}}$ & $124-19-6$ & $43,57,57$ & $\mathrm{x}$ & $\mathrm{x}$ \\
\hline 40 & 22.24 & Decanal $^{\mathrm{a}}$ & $112-31-2$ & $41,43,57$ & $\mathrm{x}$ & $\mathrm{x}$ \\
\hline 44 & 23.46 & $\begin{array}{l}\text { Benzaldehyde }{ }^{\mathrm{a}} \\
\text { Acids }\end{array}$ & $100-52-7$ & $77,105,106$ & $\mathrm{x}$ & $\mathrm{x}$ \\
\hline 36 & 21.10 & Acetic acid ${ }^{a}$ & $64-19-7$ & $43,45,60$ & $\mathrm{x}$ & $\mathrm{x}$ \\
\hline 43 & 23.20 & Propanoic acida & $79-09-4$ & $74,45,73$ & $\mathrm{x}$ & n.d. \\
\hline 57 & 27.83 & Pentanoic acid ${ }^{\mathrm{a}}$ & $109-52-4$ & $60,70,41$ & n.d. & $\mathrm{x}$ \\
\hline 62 & 30.18 & Hexanoic acid ${ }^{a}$ & $142-62-1$ & $60,73,41$ & n.d. & $\mathrm{x}$ \\
\hline 66 & 32.24 & 2-Ethylhexanoic acid & $149-57-5$ & $88,73,57$ & n.d. & $\mathrm{x}$ \\
\hline 67 & 32.40 & Heptanoic acid ${ }^{\mathrm{a}}$ & $111-14-8$ & $60,73,87$ & n.d. & $\mathrm{x}$ \\
\hline 72 & 34.49 & $\begin{array}{l}\text { octanoic acid } \\
\text { Miscellaneous }\end{array}$ & $124-07-2$ & $60,73,43$ & n.d. & $\mathrm{x}$ \\
\hline 2 & 6.48 & 2-Methyl-1,3-butadiene & $78-79-5$ & $67,68,53$ & $\mathrm{x}$ & n.d. \\
\hline 22 & 15.27 & n.i. & - & $57,55,43$ & $\mathrm{x}$ & $\mathrm{x}$ \\
\hline 23 & 15.71 & n.i. & - & $105,120,43$ & $\mathrm{x}$ & n.d. \\
\hline 27 & 16.79 & n.i. & - & $105,120,84$ & n.d. & $\mathrm{x}$ \\
\hline 35 & 19.68 & 2-Butoxy-ethanol & $111-76-2$ & $57,45,41$ & $\mathrm{x}$ & $\mathrm{x}$ \\
\hline 37 & 21.45 & $2,1{\text { meox} 2 \text { prop }^{\mathrm{d}}}$ & $20324-33-8$ & $59,103,43$ & n.d. & $\mathrm{x}$ \\
\hline 45 & 23.82 & n.i. & - & $73,43,59$ & n.d. & $\mathrm{x}$ \\
\hline 46 & 23.98 & n.i. & - & $57,82,67$ & n.d. & $\mathrm{x}$ \\
\hline 49 & 25.19 & 2etoxeth ${ }^{\mathrm{e}}$ & $111-90-0$ & $45,59,72$ & n.d. & $\mathrm{x}$ \\
\hline 50 & 25.50 & Phenylethyl acetate & $103-45-7$ & $94,43,136$ & $\mathrm{x}$ & n.d. \\
\hline 55 & 26.63 & n.i. & - & $71,57,43$ & $\mathrm{x}$ & $\mathrm{x}$ \\
\hline 56 & 26.77 & 4-tert-Butylcyclohexyl acetate & $32210-23-4$ & $57,80,73$ & n.d. & $\mathrm{x}$ \\
\hline 58 & 28.00 & Benzyl acetate & $140-11-4$ & $108,91,90$ & n.d. & $\mathrm{x}$ \\
\hline 61 & 29.19 & n.i. & - & $57,41,71$ & n.d. & $\mathrm{x}$ \\
\hline 64 & 31.19 & Benzyl alcohol ${ }^{\mathrm{a}}$ & $100-51-6$ & $79,108,107$ & n.d. & $\mathrm{x}$ \\
\hline
\end{tabular}


Table 3 (Continued)

\begin{tabular}{|c|c|c|c|c|c|c|}
\hline Peak number & R.T. (min) & Compounds & CAS number & $m / z$ & Breath & Ambient air \\
\hline 65 & 31.97 & 2-Phenyldodecane & $2719-61-1$ & $91,73,122$ & n.d. & $\mathrm{x}$ \\
\hline 68 & 32.51 & 1-Undecanol ${ }^{\mathrm{a}}$ & $112-42-5$ & $55,43,69$ & n.d. & $\mathrm{x}$ \\
\hline 69 & 33.19 & 2-Methyl-1-undecanol & $10522-26-6$ & $58,43,69$ & n.d. & $\mathrm{x}$ \\
\hline 70 & 33.77 & Phenol $^{\mathrm{a}}$ & $87-66-1$ & $94,66,65$ & $\mathrm{x}$ & $\mathrm{x}$ \\
\hline 71 & 33.87 & Isopropyl tetradecanoate & $110-27-0$ & $228,102,229$ & n.d. & $\mathrm{x}$ \\
\hline 73 & 35.19 & $\beta$-Ionone ${ }^{a}$ & 14901-07-6 & $177,119,135$ & n.d. & $\mathrm{x}$ \\
\hline 74 & 35.66 & 2-Methyl- $\beta$-ionone & $127-43-5$ & $191,121,105$ & n.d. & $\mathrm{x}$ \\
\hline 75 & 36.78 & $\beta$-Phenoxyethyl alcohol & $9004-78-8$ & $94,138,77$ & n.d. & $\mathrm{x}$ \\
\hline
\end{tabular}

n.i.: not identified.

n.d. - not detected.

a Compounds confirmed by chemical standards.

b Used fragment for area determination.

c 2,6bmethnapth: 2,6-bis(1-methylethyl)naphthalene.

d 2,1 meox2prop: 2,1-(2-methoxy-1-methylethoxy)-2-propanol.

e 2etoxeth: 2-(2-ethoxyethoxy)ethanol.

these results a standard cleaning protocol for the Tedlar ${ }^{\circledR}$ bags was established for the present study.

\subsubsection{Intra-individual variability evaluation}

The intra-individual variability was examined, comparing the data per subject from day to day, and throughout each day, by repeating breath sampling for the same child with allergic asthma over a period of 3 weeks with six daily collections $(n=18)$. This is an important factor in the evaluation of the developed methodology to determine whether a breath sample is dependent on the period of time that it is collected. Fig. 4 summarizes the results of six selected compounds that represent linear and ramified alkanes and aldehydes. Single factor ANOVA was performed to evaluate data variability and there were no significant differences between days, and throughout each day, represented by weeks 1 , 2 and $3(p<0.05)$. However, accordingly to Fig. 5 , there are intraindividual variations between samples over different days of the three weeks as well as in the same day that can be explained by several factors, as for example the circadian rhythm, and diet (sampling were performed throughout the day, before and after meals with different daily diets). It was confirmed that the child asthma status was maintained during this experiment with no occurrence of an asthma crisis. This study was performed with a single subject, and the results obtained are similar to those reported in previous study that has used a larger number of subjects [4].

\subsubsection{Exhaled breath analysis}

The developed HS/SPME-GC-qMS methodology was applied to exhaled children breath samples. Forty-four volatile compounds were identified belonging to different chemical families such as alkanes (linear and ramified), ketones, aromatic hydrocarbons, aldehydes, acids, among others (Table 3 ). The predominant group identified in exhaled breath were the alkanes ( 26 compounds). The identified compounds are also reported in other studies performed using exhaled breath [27-29].

Parallel room air sampling was also performed by the reported fact that in the environment there are a whole range of volatiles from several sources, which may influence the obtained results. Room air analysis allowed the identification of fifty-three compounds that belong to several different chemical families: alkanes (linear and ramified ketones, terpenic compounds, aromatic hydrocarbons, aldehydes, acids, among others (Table 3)). From these, twenty-one compounds were common to children exhaled breath. Compounds that were present in room air with higher areas than in breath were discarded for PLS-DA analysis, as hexane for example, among others.

\subsection{Multivariate analysis}

Twenty-eight from the forty-four volatiles were selected for multivariate analysis. This selection was made taking account the compounds that were present in all children with allergic asthma and by disregarding compounds that are known as solvents and contaminations (for example, aromatic hydrocarbons). PLS-DA was applied to the GC chromatographic unit variance scaled areas to establish a preliminary classification model and assess the relationships between the compounds and the children under study. Fig. 5a shows the scores scatter plot of the first two Latent Variables (LV1xLV2), while Fig. 5b shows the corresponding loading weights plot which establishes the contribution of each volatile metabolite that promotes the observed discrimination. The classification model was assessed by internal cross-validation (7 blocks) giving a model with 4 LVs with a classification rate of $88 \%$. A limited number of metabolites (28) were used to classify children with allergic asthma and healthy controls using discriminant analysis, with special highlight to compounds linked to oxidative stress such as alkanes and aldehydes [30]. These metabolites were not unique to children with allergic asthma and were also observed in healthy children in greater or lesser abundance as normal human metabolism generates a wide variety of metabolites. Airway inflammation plays a central role in the pathophysiology of asthma and during this process a degradation of polyunsaturated fatty acids occurs due to the imbalance between oxidants and antioxidants. This imbalance is explained by the continuous production of reactive oxygen species (ROS) caused by an influx of leukocytes characteristic of lung inflammation in asthma. During this process volatile metabolites are formed by lipid peroxidation of $\omega-3$ and $\omega-6$ polyunsaturated fatty acids [31].

From Fig. 5a, there are two relatively defined clusters with a clear tendency for the control group being associated with LV1 and LV2 negative values explained by 2,4-dimethylheptane, 4methyloctane and acetone, whereas the allergic asthma group is dispersed most probably due to the distinct allergic asthma as well as different disease stages. There are clusters for allergic asthma children for example in LVI and LV2 positive values that seems to have contribution from decane, dodecane and tetradecane. Another region is LV1 negative and LV2 positive values influenced by 2methyl-1,3-butadiene whereas the allergic asthma children that are clustered in LV1 positive region and LV2 negative values are mainly influenced by 2,2-dimethylhexane, 2,4-dimethyloctane and 2,3,6-trimethyldecane among others. $C_{13}$ alkanes were previously used to discriminate asthma patients from controls [4], being more intense in asthmatic ones. 


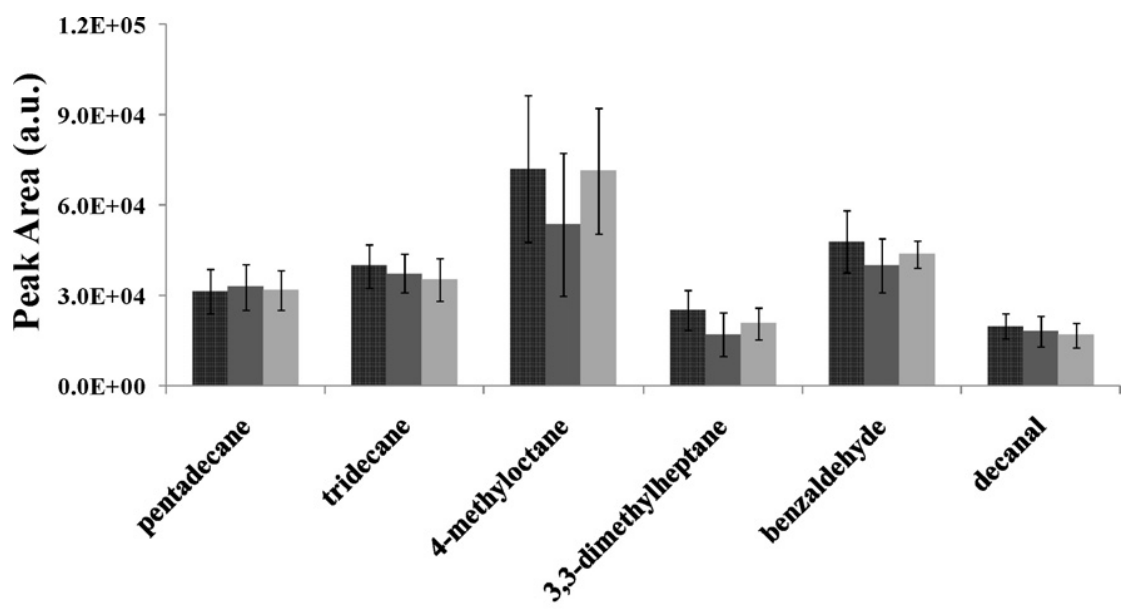

Week 1 Week 2 Week 3

Fig. 4. Evaluation of the intra-individual variability over a period of three weeks for selected group of six metabolites.
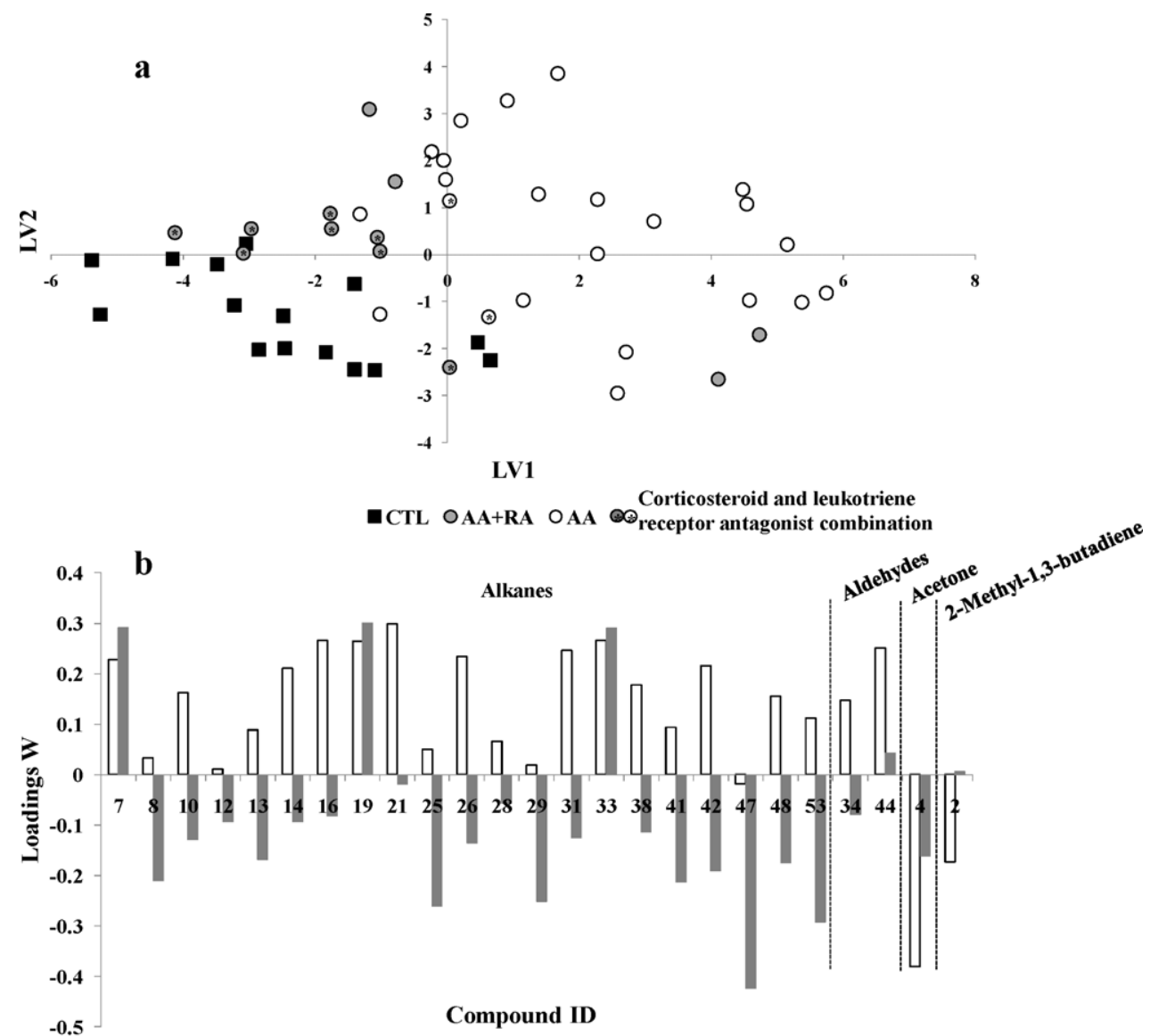

Compound ID

Fig. 5. PLS-DA LV1xLV2 scores scatter plot (a) and loading weights plot (b) of exhaled breath for allergic asthma (AA and AA+RA) and control (CTL) children. Peak identification is presented in Table 3 (2: 2-methyl-1,3-butadiene, 4: acetona, 7: decane, 8: 3,3-dimethylheptane, 10: 2,4-dimethyloctane, 12: 3-ethyl-3-methylheptane, 13 2,3,7-trimethyldecane, 14: undecane, 16: 2,3-dimethyldecane; 19: dodecane, 21: 3,9-dimethylundecane, 25: 3,6-dimethyldecane, 26: tridecane, 28: n.i. $m / z$ 43,71,57, 29: n.i. $m / z$ 71,57,43, 31: 2,3,6-trimethyldecane; 33: tetradecane, 38: pentadecane, 41: n.i. $m / z$ 43,85,71; 42: n.i. $m / z$ 71,43,57, 47: hexadecane, 48: 2 -methyltridecane, 53: 2-methylpentadecane).

Clinical data such as therapy, spirometry values, IgE values and prick test results were also available. The PLS-DA scores scatter plot was tentatively explained using clinical data. Allergic asthma is a condition associated to airspace inflammation with increasing evidence that lipid peroxidation may have an important part in the differentiating the composition of exhaled breath between allergic asthma and control group. Compounds as the identified alkanes, and that exerted statistical differences between allergic asthma and control group, might be an end-product of lipid peroxidation but other pathways cannot be excluded. Allergic rhinitis is symptomatic disorder of the nose induced after allergen exposure, an IgE mediated inflammation of the membranes lining of 
the nose. Both allergic asthma and rhinitis are systemic inflammatory conditions and usually over $80 \%$ of asthmatics have rhinitis and $10-40 \%$ of patients with rhinitis have asthma. In the studied population, $63 \%$ were diagnosed with allergic asthma (AA) while $37 \%$ with allergic asthma and allergic rhinitis $(A A+A R)$ and from the PLS-DA we denote that AA + AR cases are predominantly in LV1 negative LV2 positive whereas for AA children there is a higher scattering throughout LV1 axis. Both diseases are inflammatory diseases; however inflammation in rhinitis is concentrated in the nose while in allergic asthma occurs in the airways modifying the volatile composition as observed in Fig. $5 a$.

Prick tests were also available with $54 \%$ of the studied cases being allergic to dust mites, $9 \%$ dust mites and gramineae, $9 \%$ dust mites and cat fur and 3\% to dust mite, gramineae and car fur. Due to a higher number of cases, the cases with positive prick tests to dust mites are highlighted in the PLS-DA and from this data we observe a high dispersion through LV1 axis. As for the other possible combinations, a higher number of cases are necessary to exert any conclusions.

Several medication combinations are prescribed by clinicians to control allergic asthma and rhinitis. Inhaled corticosteroids prevent asthma symptoms by blocking the late-phase immune reaction to an allergen, reduce airway hypersponsiveness and decreases inflammation and inhibit inflammatory cells such as mast cells, eosinophils and basophils. Leukotriene receptor antagonist or leukast are drugs that inhibit the leukotrienes receptors, compounds that are produced by the immune system that cause inflammation in asthma and that constrict airways whereas a histamine antagonist or antihistamine is an agent that inhibits the action of histamine that is released in excess by an allergic reaction. Bronchodilators are used to dilate the bronchi and bronchioles decreasing airway resistance and thereby facilitating airflow. In our population, the three most frequent combinations were: inhaled corticosteroids and leukotriene receptor antagonist, inhaled corticosteroids and anti-histamines or inhaled corticosteroids and bronchodilator. As far as medication effects on breath volatile composition that should reflect the inflammation, we observed in the PLS-DA (highlighted with an asterisk in Fig. 5a) differences between the exhaled breath of children that used a combination between corticosteroid and leukotriene receptor antagonist for asthma control as these individuals presented themselves closer to control subjects than other subjects that were under corticosteroid and anti-histaminic or corticosteroid and bronchodilator therapy. This occurrence may be explained by the properties of the combination of inhaled corticosteroids and leukotriene receptor antagonist as both decrease inflammation consequently affecting the volatile composition of exhaled breath and thereby inflammation compounds such as linear and ramified alkanes.

\section{Conclusions}

In this study, we report the development of HS-SPME/GC-qMS methodology using a full factorial design. Breath sampling related subjects such as breath sampling containers and their cleaning, as well as an important parameter like intra-individual variability were also determined. The optimization of SPME parameters was done with selected standards representative of different chemical families previously reported in human breath $[8,15]$ and the higher extraction efficiency was obtained with the mixed phase DVB/CAR/PDMS fibre with an extraction of $60 \mathrm{~min}$ and a temperature of $22^{\circ} \mathrm{C}$.

The comparison between $1 \mathrm{~L}$ Tedlar ${ }^{\circledR}$ gas sampling bags and BIOVOC $^{\circledR}$, for breath collection, showed Tedlar ${ }^{\circledR}$ gas sampling bags to be the most adequate containers for collecting breath samples. The cleaning protocol for the Tedlar ${ }^{\circledR}$ bags was also established and consists of flushing the bag with nitrogen ten times, preceded by vacuum. As for intra-individual variability, results show that there was no statistical difference between sampling exhaled breath within the same day as well as sampling between different weeks, if the asthma status is maintained.

The developed methodology was then successfully applied to breath samples of allergic asthma children and healthy controls, allowing the identification of forty-four volatiles from different chemical families, namely: alkanes (linear and ramified) ketones, aromatic hydrocarbons, aldehydes, acids, among others. Multivariate studies were performed (PLS-DA) using a set of 28 selected metabolites and the corresponding loadings suggested the compounds that promoted the observed distinction between allergic asthma and control children. The allergic asthma population was characterized mainly by the compounds possibly linked to oxidative stress, such as alkanes and aldehydes, which is a characteristic of airway inflammation. Furthermore, more detailed information can be achieved about the asthma metabolic volatile profile by the proposed approach. The advantage of the developed methodology was observed when the volatile metabolic data processed by PLS-DA was explained using the clinical data. Further studies are being performed increasing the number of allergic asthma and healthy children.

Although the number of cases studied is relatively small (50), the obtained results generated fundamental information which represents the scientific basis for the definition of a rapid and noninvasive diagnostic tool. The results of this study provided a novel methodological approach to characterise allergic asthma as a function of its metabolomic patterns, which will open new strategies to early diagnosis, therapy monitoring, and understanding the asthma pathogenesis that affects millions around the world.

\section{Acknowledgments}

M. Caldeira thanks FCT (Fundação para a Ciência e Tecnologia) for his PhD grant (SFRH/BD/40374/2007). The authors are grateful to the donors that kindly supplied the samples and to Paediatric Service of the Hospital D. Pedro (Aveiro, Portugal) for the conditions to perform this study and for the financial support of the Research Unit 62/94, QOPNA.

\section{References}

[1] M.E. Van den Akker-van Marle, J. Bruil, S.B. Detmar, Allergy 60 (2005) 140

[2] M.D. Lim, A. Dickherber, Anal. Chem. 83 (2011) 8.

[3] L. Pauling, A.B. Robinson, R. Teranishi, P. Cary, Proc. Natl. Acad. Sci. U. S. A. 68 (1971) 2374.

[4] J.W. Dallinga, C.M.H.H.T. Robroeks, J.J.B.N. Van Berkel, E.J.C. Moonen, R.W.L. Godschalk, Q. Jobsis, E. Dompeling, E.F.M. Wouters, F.J. Van Schooten, Clin. Exp. Allergy 40 (2009) 68.

[5] M. Barker, M. Hengst, J. Schmid, H.-J. Buers, B. Mittermaier, D. Klemp, R. Koppmann, Eur. Respir. J. 27 (2006) 929.

[6] I. Horváth, Z. Lázár, N. Gyulai, M. Kollai, G. Losonczy, Eur. Respir. J. 34 (2009) 261.

[7] E.M. Gaspar, A.F. Lucena, J.D. da Costa, H.C. das Neves, J. Chromatogr. A 1216 (2009) 2749.

[8] T. Ligor, M. Ligor, A. Amann, C. Ager, M. Bachler, A. Dzien, B. Buszewski, J. Breath Res. 2 (2008) 1.

[9] J.-H. Lee, S.M. Hwasng, D.W. Lee, G.S. Heo, B Korean Chem. Soc. 23 (2002) 488.

[10] J.J.B.N. Van Berkel, J.W. Dallinga, G.-M. Moller, R.W.L. Godschalk, E. Moonen, E.F.M. Wouters, F.J. Van Schooten, Respir. Med. 104 (2010) 557.

[11] M. Phillips, V. Basa-Dalay, G. Bothamley, R. Cataneo, P. Lam, M. Natividad, P. Schmitt, J. Wai, Tuberculosis 90 (2010) 145

[12] S. Kischel, W. Miekisch, A. Sawacki, E. Straker, P. Trefz, A. Amann, J. Schubert, Clin. Chim. Acta 411 (2010) 1637.

[13] M.-R. Lee, Y.C. Yeh, W.S. Hsiang, C.C. Chen, J. Chromatogr. B 707 (1998) 91.

[14] G. Deng, J. Zhang, X. Yu, W. Zhang, X. Zhang, J. Chromatogr. B 810 (2004) 269.

[15] G. Song, T. Qin, H. Liu, G.B. Xu, Y.P. Pan, F.X. Xiong, K.S. Gu, G.P. Sun, Z.D. Chen, Lung Cancer 67 (2009) 227.

[16] L.T. McGrath, R. Patrick, P. Mallon, L. Dowey, B. Silke, W. Norwood, S. Elborn, Eur. Respir. J. 16 (2008) 1065.

[17] L.C. Amorim, Z. Cardeal, J. Chromatogr. B 853 (2007) 1. 
[18] S.L. Nordvall, C. Janson, P. Kalm-Stephens, T. Foucard, K. Torén, K. Alving, Allergy 60 (2005) 469

[19] C.M. Robroeks, K.D. van de Kant, Q. Jobsis, H.J. Hendriks, R. van Gentw, E.F Woutersz, J.G. Damoiseaux, A. Bastz, W.K. Wodzigk, E. Dompeling, Clin. Exp. Allergy 37 (2007) 1303.

[20] K. Schwarz, W. Filipaik, A. Amann, J. Breath Res. 3 (2009) 1.

[21] A. Mashir, R.A. Dweik, Adv. Powder Technol. 20 (2009) 420.

[22] P. Mochalski, B. Wzorek, I. Sliwka, A. Amann, J. Chromatogr. B 877 (2009) 189.

[23] J.J.B.N. Van Berkel, J.W. Dallinga, G.-M. Moller, R.W.L. Godschalk, E. Moonen, E.F.M. Wouters, F.J. Van Schooten, J. Chromatogr. B 861 (2008) 101.

[24] L. Eriksson, E. Johansson, N. Kettaneh, N. Wold, S. Wold, Multi and Megavariate Data Analysis, Principles and Applications, Umetrics AB, Umea, Sweden, 2001.

[25] H. Yu, L. Xu, P. Wang, J. Chromatogr. B 826 (2005) 69.

[26] M. Steeghs, S. Cristescu, F.J. Harren, Physiol. Meas. 28 (2007) 73.
[27] M. Ligor, T. Ligor, A. Bajtarevic, C. Ager, M. Pienz, M. Klieber, H. Denz, M. Fiegl, W. Hilbe, W. Weiss, P. Lukas, H. Jamnig, M. Hackl, B. Buszewski, W. Miekisch, J. Schubert, A. Amann, Clin. Chem. Lab. Med. 47 (2009) 550.

28] W. Filipiak, A. Sponring, A. Filipiak, C. Ager, J. Schubert, W. Miekisch, A. Amann, J. Troppmair, Cancer Epidemiol. Biomarkers Prev. 19 (2010) 182.

[29] A. Bajtarevic, C. Ager, M. Pienz, M. Klieber, K. Schwarz, M. Ligor, T. Ligor, W. Filipiak, H. Denz, M. Fiegl, W. Hilbe, W. Weiss, P. Lukas, H. Jamnig, M. Hackl, A. Haidenberger, B. Buszewski, W. Miekisch, J. Schubert, A. Amann, BMC Cancer 9 (2009) 348.

[30] M. Phillips, R.N. Cataneo, B.A. Ditkoff, P. Fisher, J. Greenberg, R. Gunawardena, C.S. Kwon, F. Rahbari-Oskoui, C. Wong, Breast J. 9 (2003) 184.

[31] C.M. Robroeks, J. van Berkel, J. Dallinga, Q. Jobsis, L. Zimmermann, H. Hendriks, M. Wouters, C. Grinten, K. Kant, F. Schooten, E. Dompeling, Pediatr. Res. 68 (2010) 75. 